\title{
PERENCANAAN PENGGUNAAN LAHAN KOMODITAS UNGGULAN PERKEBUNAN DI KABUPATEN TANAH DATAR
}

\author{
Landuse Planning of Superior Estate Commodities in Tanah Datar \\ Regency
}

\section{Astriana Rahmi Setiawati ${ }^{1}$, Santun R.P Sitorus ${ }^{2}$, Widiatmaka ${ }^{3}$}

Diterima: 8 Maret 2016 Disetujui: 11 Juli 2016

\begin{abstract}
Abstrak: Tanah Datar merupakan salah satu kabupaten di Provinsi Sumatra Barat yang memiliki potensi yang cukup besar dalam bidang pertanian, dimana lebih dari $70 \%$ dari masyarakatnya merupakan petani. Akan tetapi, pendapatan daerah kabupaten ini lebih rendah dibandingkan dengan kabupaten lainnya di Sumatera Barat. Penelitian ini bertujuan untuk: (1) mengidentifkasi komoditas unggulan perkebunan Kabupaten Tanah Datar; (2) mengidentifikasi dan mendeliniasi penggunaan lahan eksisting Kabupaten tanah Datar; (3) mengevaluasi ketersediaan lahan dan kesesuaian lahan untuk pengembangan komoditas unggulan perkebunan di Kabupaten Tanah Datar; (4) menyusun arahan rencana penggunaan lahan untuk komoditas unggulan perkebunan Kabupaten Tanah Datar. Evaluasi kesesuain lahan komoditas unggulan dilakukan dengan menggunakan metode matching antara crops requirement dan karakteristik lahan. Berdasarkan hasil penelitian diketahui bahwa ketersediaan lahan untuk pengembangan komoditas unggulan adalah sebanyak 38.210 ha yang mana sesuai untuk kopi robusta (X koto); pala (batipuh); kakao (Batipuh selatan, Rambatan, Limo kaum, Tanjung emas, dan Lintau buo utara); karet (Padang gantiang); cassievera (Pariangan dan Salimpauang); vanilla (sungai tarap); dan kopi arabika (Salimpauang).
\end{abstract}

Kata kunci: ketersediaan, metoda matching, kesesuaian, komoditas unggulan.

Abstract: Tanah Datar is one of regency in West Sumatera that has a great potential in agriculture, which is more than $70 \%$ of its population are farmers. Unfortunately, the economic income of this regency is lowest than another regency in West Sumatera. This research aimed: (1) to identify superior estate comodities of Tanah Datar Regency; (2) to identify present land use of Tanah Datar Regency; (3) to analyze land availability and to evaluate land suitability of superior estate commodities; (4) to arrange the direction of superior estate commodities development. Land suitability evaluation was done by using the matching method between land characteristics and crops requirement. The study showed that the available land for development of superior comodities is about 38.210 ha which is suitable for robusta coffee (X koto); nutmeg (Batipuh); cocoa (Batipuh selatan, Rambatan, Limo kaum, Tanjung emas, and Lintau buo utara); rubber (Padang gantiang); cassievera (Pariangan and Salimpauang); vanilla (Sungai tarap); and arabica coffee (Salimpauang), respectively.

Keywords: availability, matching method, suitability, superior comodity.

\footnotetext{
${ }^{1}$ Program Studi Ilmu Tanah, Sekolah Pascasarjana, Institut Pertanian Bogor

${ }^{2}$ Program Studi Ilmu Perencanaan Wilayah, Sekolah Pascasarjana, Institut Pertanian Bogor
}

Korespondensi: astriana.harun@yahoo.com 



\section{PENDAHULUAN}

Keputusan dalam penggunaan lahan selalu menjadi bagian penting dalam kehidupan manusia, dimana dalam proses perencanaan penggunaan lahan tersebut diawali dengan proses evaluasi lahan. Evaluasi terhadap penggunaan lahan pada hakekatnya merupakan suatu proses yang terjadi secara terus menerus (continuing process) dan "multi-konsep", dimana sangat dipengaruhi oleh tujuan dari pengguna lahan itu sendiri, baik dengan tujuan ekonomi, lingkungan, maupun tujuan sosial (Baja 2012).

Fungsi evaluasi sumberdaya lahan adalah memberikan pengertian tentang hubunganhubungan antara kondisi lahan dan penggunaannya serta memberikan kepada perencana sebagai perbandingan dan alternatif pilihan penggunaan yang dapat diharapkan berhasil. Penentuan kesesuaian lahan dengan persyaratan tumbuh tanaman sangat diperlukan terutama dalam perencanaan pengembangan komoditas pertanian, khususnya dalam bidang perkebunan (Boix dan Zink 2008). Hal ini penting karena untuk mengetahui potensi pengembangan tanaman perkebunan sangat diperlukan informasi kesesuaian komoditas berdasarkan kelas kesesuaian lahan sehingga tanaman tersebut mampu tumbuh selaras dengan iklim dan kondisi lahan yang ada (Makaborang et al. 2009). Babalola et al. (2011) menyatakan bahwa untuk pengembangan suatu komoditas diperlukan beberapa persyaratan seperti adanya kesesuaian lahan dalam pemilihan komoditas unggulan pada suatu wilayah pengembangannya, adanya potensi sumberdaya lahan wilayah berupa lahan, agroklimat, tenaga kerja, sarana maupun prasarana sosial ekonomi serta kondisi sosial ekonomi dan budaya masyarakat. Prinsip evaluasi kesesuaian lahan pertanian adalah untuk memprediksi potensi dan keterbatasan lahan untuk produksi tanaman (Ranya et al. 2013).

Komoditas unggulan merupakan komoditas andalan yang memiliki posisi strategis untuk dikembangkan disuatu wilayah yang penetapannya didasarkan pada berbagai pertimbangan, baik secara teknis (kondisi tanah dan iklim) maupun sosial ekonomi dan kelembagaan. Berdasarkan Balai Penelitian Tanaman Pangan (BPTP) Sumatra Barat tahun 2014, pertumbuhan sektor pertanian relatif lambat, dimana sektor perkebunan hanya menyumbang 4,08 \% dari total PDRB Sumatra Barat. Sementara itu, terdapat adanya peningkatan produksi dari beberapa komoditi perkebunan. Berdasarkan Badan Pusat Statistik Kabupaten Tanah Datar (2014), terdapat komoditi perkebunan yang cukup menjanjikan terhadap perekonomian masyarakat karena komoditinya dapat diekspor ke luar negeri, seperti produksi kakao, kopi robusta, kopi arabika dan kemiri. Informasi potensi sumberdaya lahan perkebunan di Kabupaten Tanah Datar masih terbatas, dimana pada saat sekarang ini belum ada informasi mengenai kesesuaian lahan komoditas unggulan perkebunan setiap kecamatan di kabupaten ini. Penetapan komoditas unggulan disuatu wilayah menjadi suatu keharusan dengan pertimbangan bahwa komoditas tersebut mampu bersaing secara berkelanjutan dengan komoditas yang sama yang dihasilkan oleh wilayah lain atau komoditas tersebut unggul secara komparatif dan kompetitif serta memiliki keterkaitan antar sektor yang kuat sehingga berpotensi sebagai motor penggerak perekonomian wilayah. Oleh karena itu, pengembangan ekonomi wilayah melalui pengembangan komoditas unggulan akan mempercepat pertumbuhan ekonomi suatu daerah, sehingga perencanaan penggunaan lahan dengan mempertimbangkan kesesuaian lahan komoditas unggulan perkebunan penting dilakukan agar dapat memberikan informasi kesesuaian lahan komoditas tertentu untuk peningkatan pendapatan masyarakat dan pengembangan wilayahnya.

Penelitian ini bertujuan untuk merencanakan penggunaan lahan untuk pengembangan komoditas unggulan perkebunan di Kabupaten Tanah Datar. Untuk mencapai tujuan tersebut, maka dilakukan beberapa tahapan penelitian yang bertujuan untuk: (1) Mengidentifikasi komoditas unggulan perkebunan Kabupaten Tanah Datar; (2) Mengidentifikasi dan mendeliniasi penggunaan lahan eksisting Kabupaten Tanah Datar; (3)

TATALOKA - VOLUME 18 NOMOR 3 - AGUSTUS 2016 - p ISSN 0852-7458 - e ISSN 2356-0266 
Mengevaluasi ketersediaan lahan dan kesesuaian lahan untuk pengembangan komoditas unggulan perkebunan di Kabupaten Tanah Datar; (4) Menyusun arahan rencana penggunaan lahan untuk komoditas unggulan Kabupaten Tanah Datar.

\section{METODE}

\section{Lokasi dan Waktu Penelitian}

Penelitian ini dilaksanakan pada bulan Desember 2014 - Agustus 2015 di Kabupaten Tanah Datar, Propinsi Sumatera Barat. Secara geografis Kabupaten Tanah Datar terletak pada posisi $00^{\circ} 17^{\prime \prime} \mathrm{LS}-00^{\circ} 39^{\prime \prime} \mathrm{LS}$ dan $100^{\circ} 19^{\prime \prime} \mathrm{BT}-100^{\circ} 51^{\prime \prime} \mathrm{BT}$, dengan luas wilayah 1.336 $\mathrm{Km}^{2}$ dan terdiri dari 14 Kecamatan. Lokasi penelitian secara spasial dapat dilihat pada Gambar 1.

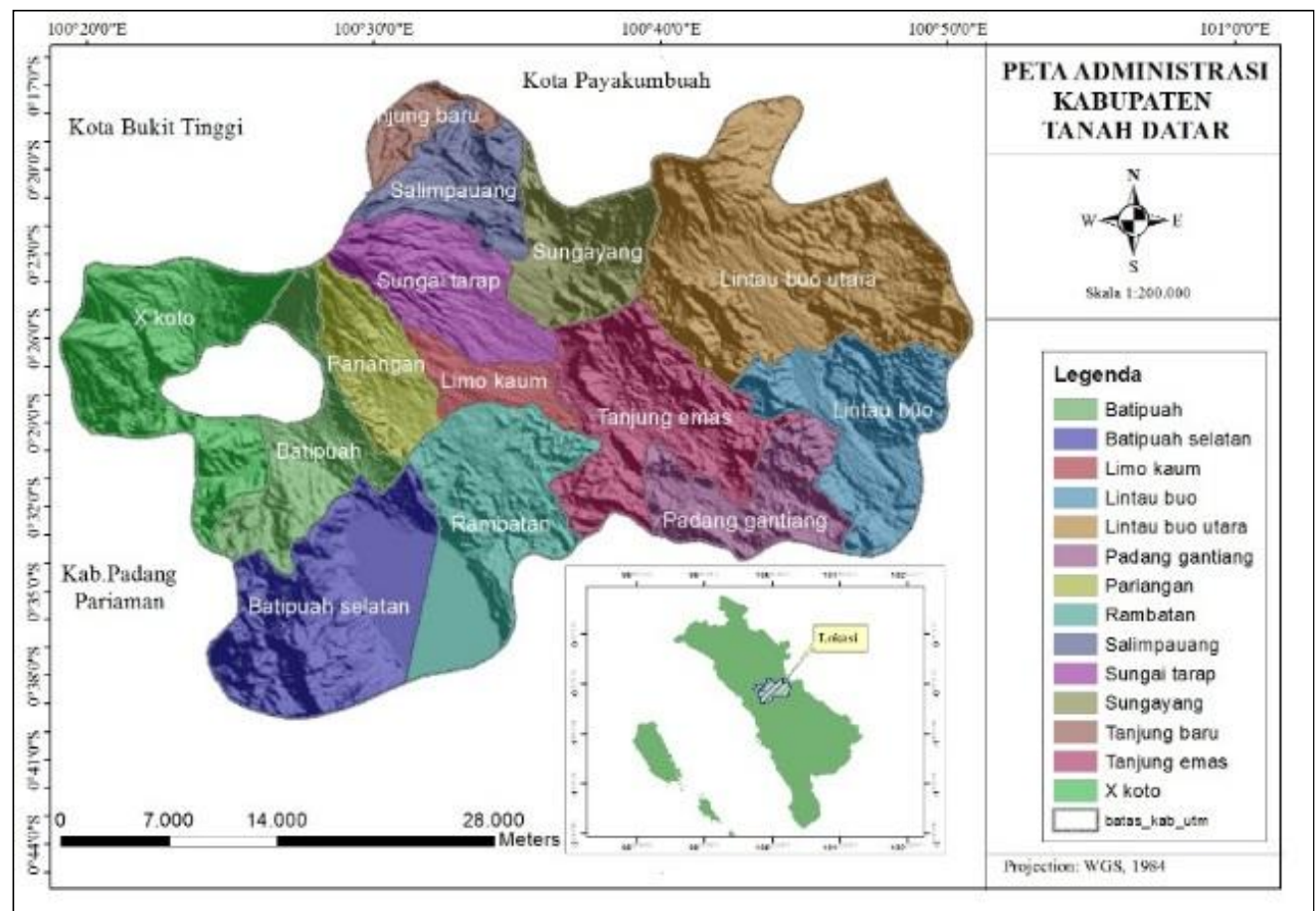

Gambar 1. Peta Administrasi Kabupaten Tanah Datar

\section{Jenis dan Sumber Data}

Jenis data terdiri dari data sekunder dan data primer. Data sekunder diperoleh melalui Badan Pusat Statistik (BPS) Sumatera Barat dan Balai Besar Penelitian dan Pengembangan Sumberdaya Lahan Pertanian (BBSDLP). Data primer diperoleh melalui interpretasi citra satelit dan analisis sifat fisika dan kimia tanah di laboratorium. 


\section{Analisis Data}

\section{Identifikasi Komoditas Unggulan dengan metode LQ dan SSA}

Location Quotient (LQ) digunakan untuk menunjukkan ada tidaknya pemusatan aktifitas komoditas pertanian pada kecamatan di Kabupaten Tanah Datar. Menurut Blakely (1994) persamaan indeks LQ dirumuskan sebagai berikut:

Dimana:

$$
L \mathrm{j}=\frac{X / X}{X \cdot j / X . .}
$$

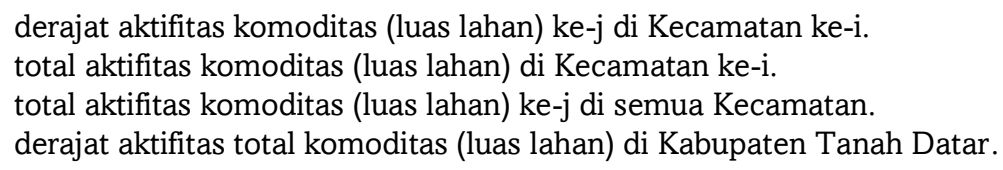

Shift Share Analysis (SSA) merupakan salah satu analisis untuk memahami pergeseran struktur aktivitas di suatu lokasi tertentu dibandingkan dengan suatu referensi (cakupan wilayah yang lebih luas) dalam dua titik waktu. SSA juga menjelaskan kemampuan berkompetisi (competitiveness) aktivitas tertentu di suatu wilayah tertentu serta menjelaskan kinerja aktivitas tertentu di wilayah tertentu. Rumus SSA adalah sebagai berikut.

$$
\mathrm{SSA}=\left[\mathrm{X}_{\mathrm{I}(\mathrm{t} 1)} / \mathrm{X}_{\mathrm{I}(\mathrm{t} 0))}\right]-\left[\mathrm{X}_{\mathrm{J}(\mathrm{t} 1)} / \mathrm{X}_{\mathrm{J}(\mathrm{t}))}\right] \text { (Rustiadi et al. 2011) }
$$

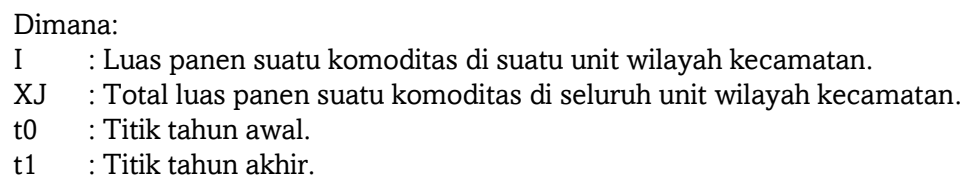

Kriteria penilaian dalam penentuan komoditas unggulan adalah jika nilai indeks LQ lebih besar atau sama dengan satu (LQ $\geq 1)$ dan nilai SSA (+).

\section{Analisis Penggunaan Lahan}

Tahapan yang digunakan pada interpretasi citra LANDSAT TM 8 untuk mengklasifikasikan penggunaan lahan di Kabupaten Tanah Datar adalah: (1) Pemotongan batas area penelitian; (2) Rektifikasi citra LANDSAT TM 8; (3) Klasifikasi penggunaan lahan.

\section{Evaluasi ketersediaan lahan dan kesesuaian lahan komoditas unggulan Kabupaten Tanah Datar}

Untuk mengevaluasi ketersediaan lahan untuk pengembangan komoditas unggulan maka dilakukan analisis dari tiga peta yaitu: (1) peta pola ruang RTRW Kabupaten Tanah Datar tahun 2011 - 2031; (2) peta peruntukan kawasan hutan dari kementerian kehutanan 2012; (3) peta penggunaan lahan eksisting hasil interpretasi citra satelit. Sebelum melakukan evaluasi kesesuaian lahan, dilakukan terlebih dahulu penentuan Satuan Peta Lahan (SPL). SPL didapatkan dengan cara overlay dari beberapa peta yaitu : (1) Peta Satuan Lahan dan Tanah skala 1:250.000 (lembar Padang 0715 dan lembar solok 0815); (2) Data DEM yang kemudian di interpretasikan menjadi Peta Kemiringan Lahan skala 1:50.000; (3) Peta Penggunaan Lahan eksisting skala 1:50.000; dan (4) Peta Geologi skala 1:250.000.

Evaluasi lahan dilakukan dengan menggunakan metoda matching (pendekatan faktor pembatas) dari crops requirement komoditas unggulan hasil analisis LQ dan SSA dengan 
karakteristik lahan dan iklim. Kriteria kesesuaian lahan berpedoman kepada petunjuk teknis Evaluasi Lahan untuk Komoditas Pertanian oleh Balai Besar Penelitian dan Pengembangan Sumber Daya Lahan Pertanian (2011).

\section{Arahan penggunaan lahan untuk perencanaan pengembangan komoditas unggulan}

Arahan rencana penggunaan lahan untuk komoditas unggulan disusun dengan mempertimbangkan: (1) pola tanam (pengamatan lapang); (2) total luas tanam; (3) total produksi; dan (4) kelas kesesuian lahan komoditas unggulan.

\section{HASIL DAN PEMBAHASAN}

\section{Identifikasi Komoditas Unggulan Perkebunan Kabupaten Tanah Datar}

Komoditas unggulan merupakan komoditas yang diusahakan pada daerah setempat yang memiliki sifat-sifat unggul bagi daerah tersebut bila dibandingkan dengan daerah lainnya (Rositadevy 2007). Data yang digunakan dalam menghitung nilai LQ dan SSA sektor pertanian adalah data luas panen masing-masing komoditas pada tahun 2007 dan 2014 dengan jumlah tujuh belas komoditas tanaman perkebunan. Hasil analisis LQ dan SSA komoditas perkebunan Kabupaten Tanah Datar disajikan pada Tabel 1.

\begin{tabular}{lll}
\multicolumn{2}{l}{ Tabel 1. Daftar Komoditas Unggulan Perkebunan per Kecamatan di Kabupaten Tanah Datar } \\
\hline No & \multicolumn{1}{c}{ Kecamatan } & \multicolumn{1}{c}{ Komoditas Unggulan } \\
\hline 1 & X Koto & Kopi robusta \\
2 & Batipuh & Kelapa dan pala \\
3 & Batipuh Selatan & Kakao, kelapa, cengkeh, cassievera, \\
& & gardamunggu, kapok, pala, dan kemiri. \\
4 & Pariangan & Cengkeh, cassievera, aren, dan pala. \\
5 & Rambatan & Kakao, cengkeh, dan merica. \\
6 & Lima Kaum & Kakao, kelapa, pala, dan kemiri. \\
7 & Tanjung Emas & Kakao dan kelapa \\
8 & Padang Gantiang & Karet \\
9 & Lintau Buo & - \\
10 & Lintau Buo Utara & Kakao dan tebu \\
11 & Sungayang & Cassievera dan aren \\
12 & Sungai Tarab & Vanili \\
13 & Salimpauang & Kopi arabika dan tebu \\
14 & Tanjung Baru & Kopi robusta dan tebu \\
\hline
\end{tabular}

Komoditas unggulan suatu wilayah diidentifikasikan dengan nilai LQ yang lebih besar dari 1 dan nilai SSA yang positif. Berdasarkan Tabel 1 dapat dilihat bahwa Kecamatan Batipuh Selatan memiliki komoditas unggulan terbanyak (8 komoditas) dibandingkan dengan kecamatan lainnya. Sementara itu, Kecamatan Lintau Buo tidak memiliki komoditas unggulan.

\section{Deliniasi Penggunaan Lahan Aktual Kabupaten Tanah Datar}

Identifikasi penggunaan lahan aktual merupakan hal terpenting yang harus dilakukan sebelum melakukan perencanaan terhadap suatu lahan. Penggunaan lahan aktual akan menentukan apakah lahan tersedia atau tidak tersedia untuk rencana penggunaan lahan. Peta penggunaan lahan aktual disajikan pada Gambar 2.

Datasets penggunaan lahan membantu dalam identifikasi lokasi, intensitas, dan tingkat aktivitas manusia yang penting untuk perencanaan (Hansen et al. 2000). Pola penggunaan lahan (penutupan dan penggunaan lahan) mencerminkan karakter masyarakat dalam berinteraksi dengan lingkungan (lahan), sehingga memungkinkan untuk melihat perbedaan 
sistem ekonomi dan sosial yang menempati lingkungan yang sama (Ganasri dan Dwarakish 2015). Berdasarkan hasil interpretasi citra satelit LANDSAT 8 dan dibantu dengan google earth serta ground check, diketahui bahwa penggunaan lahan aktual (2014) Kabupaten Tanah Datar terdiri dari: hutan primer (37,25\%); hutan sekunder (19,79\%); kebun campuran $(7,51 \%)$; ladang $(2,54 \%)$; sawah $(19,95 \%)$; semak belukar $(0,66 \%)$;lahan terbuka $(1,01 \%)$; lahan terbangun (5,03\%); dan tubuh air $(6,28 \%)$.

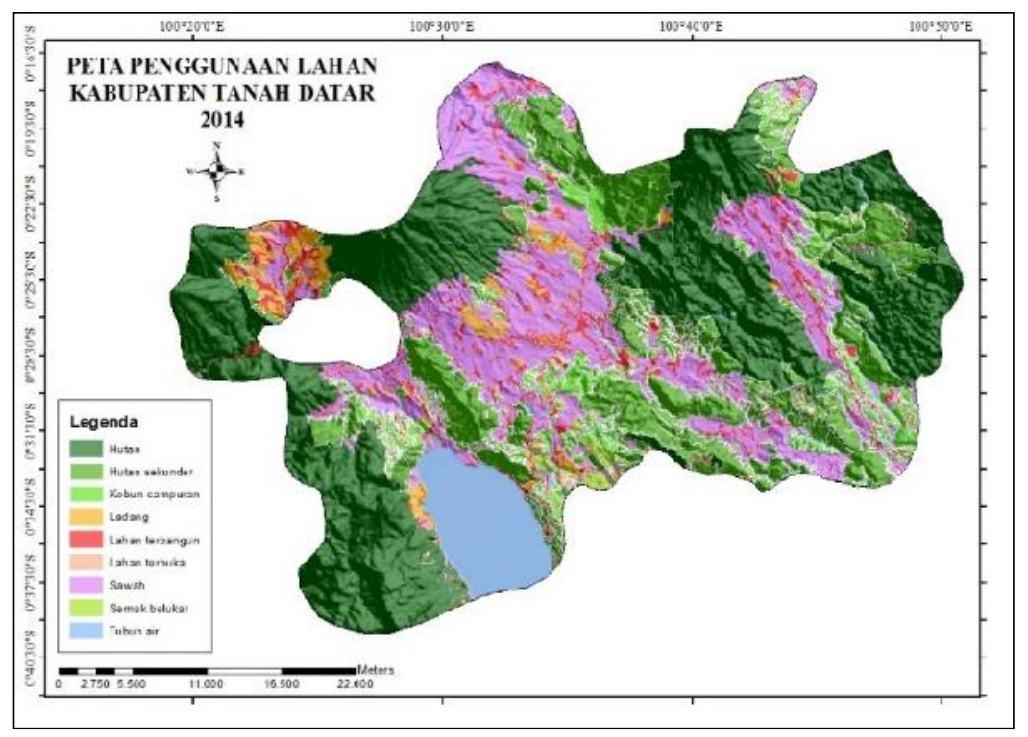

Gambar 2. Peta Penggunaan Lahan Kabupaten Tanah Datar Tahun 2014

\section{Ketersediaan Lahan dan Kesesuaian Lahan Komoditas Unggulan Perkebunan}

\section{Ketersediaan lahan}

Ketersediaan lahan merupakan langkah utama yang harus dilakukan dalam kegiatan evaluasi lahan untuk tujuan penggunaan tertentu. Ketersediaan lahan untuk pengembangan komoditas unggulan Kabupaten Tanah Datar disajikan pada Tabel 2.

Tabel 2. Ketersediaan lahan untuk perencanaan komoditas unggulan

\begin{tabular}{|c|c|c|c|c|c|c|}
\hline \multicolumn{6}{|c|}{ Penggunaan Lahan } & \multirow[t]{2}{*}{ Ketersediaan Lahan } \\
\hline RTRW* & $\begin{array}{l}\text { Luas } \\
\text { (ha) }\end{array}$ & $\begin{array}{l}\text { Kawasan } \\
\text { hutan** }\end{array}$ & $\begin{array}{l}\text { Luas } \\
\text { (ha) }\end{array}$ & $\begin{array}{l}\text { Penggunaan Lahan } \\
\text { aktual } * * \star\end{array}$ & $\begin{array}{l}\text { Luas } \\
\text { (ha) }\end{array}$ & \\
\hline Budidaya & 81.708 & $\begin{array}{l}\text { - APL (Areal } \\
\text { penggunaan } \\
\text { lain) }\end{array}$ & 71.555 & $\begin{array}{l}\text { Hutan sekunder } \\
\text { Kebun campuran } \\
\text { Semak belukar }\end{array}$ & $\begin{array}{l}27.051 \\
10.264 \\
895\end{array}$ & Tersedia \\
\hline Lindung & & & & Hutan primer & 50.925 & Tidak tersedia \\
\hline $\begin{array}{l}\text {-Hutan } \\
\text { lindung }\end{array}$ & 20.162 & $\begin{array}{l}\text { Cagar alam } \\
\text { darat }\end{array}$ & 18.380 & Lahan terbuka & 1.386 & \\
\hline Cagar alam & 21.856 & Hutan lindung & 28.755 & Lahan terbangun & 6.840 & \\
\hline $\begin{array}{l}\text { Hutan } \\
\text { produksi }\end{array}$ & 8.951 & $\begin{array}{l}\text { Hutan } \\
\text { produksi }\end{array}$ & 10.300 & Ladang & 3.474 & \\
\hline $\begin{array}{l}\text { Hutan } \\
\text { produksi } \\
\text { terbatas }\end{array}$ & 732 & $\begin{array}{l}\text { Hutan } \\
\text { produksi } \\
\text { terbatas }\end{array}$ & 660 & Sawah & 27.267 & \\
\hline
\end{tabular}




\begin{tabular}{l|ccccc}
\hline \multicolumn{1}{c}{ RTRW* } & $\begin{array}{c}\text { Luas } \\
\text { (ha) }\end{array}$ & $\begin{array}{c}\text { Kawasan } \\
\text { hutan }\end{array}$ & $\begin{array}{c}\text { Luas } \\
\text { (ha) }\end{array}$ & $\begin{array}{c}\text { Penggunaan Lahan } \\
\text { aktual }\end{array}$ & $\begin{array}{c}\text { Luas } \\
\text { (ha) }\end{array}$ \\
\hline $\begin{array}{l}\text {-Hutan } \\
\text { produksi } \\
\text { konversi }\end{array}$ & 97 & & & & \\
\hline
\end{tabular}

Ketersediaan lahan untuk pengembangan komoditas unggulan dilakukan dengan cara mempertimbangkan pola ruang RTRW dan status kawasan hutan dan kemudian ditumpang tindihkan dengan peta penggunaan lahan eksisting terutama untuk mengidentifikasi jenis penggunaan lahan sekarang yang tidak atau kurang produktif. Oleh karena itu hutan sekunder, kebun campuran dan semak belukar menjadi pilihan untuk pengembangan komoditas unggulan perkebunan dengan total luasan 38.210 ha dan penggunaan lahan ini berada pada kawasan budidaya.

\section{Kesesuaian lahan}

Berdasarkan hasil penilaian komoditas unggulan antara crops requirement dengan karakteristik lahan, maka didapatkan kesesuaian lahan untuk masing-masing komoditas unggulan disetiap kecamatan yang disajikan pada Tabel 3.

Tabel 3. Kesesuaian Lahan Komoditas Unggulan Kabupaten Tanah Datar

\begin{tabular}{|c|c|c|c|c|c|c|c|c|}
\hline \multirow[b]{2}{*}{ No } & \multirow[b]{2}{*}{ Kecamatan } & \multicolumn{7}{|c|}{ Komoditas Unggulan } \\
\hline & & Karet & $\begin{array}{l}\text { Kopi } \\
\text { arabika }\end{array}$ & $\begin{array}{l}\text { Kopi } \\
\text { robusta }\end{array}$ & Kakao & Kelapa & Cengkeh & cassievera \\
\hline 1. & $\mathrm{X}$ koto & & & N, S3* & & & & \\
\hline 2. & Batipuh & & & & & $\mathrm{N}, \mathrm{S} 3 * \star$ & & \\
\hline 3. & Batipuh selatan & & & & $\mathrm{N}, \mathrm{S} 3 *$ & $\mathrm{~N}, \mathrm{~S} 3 * \star$ & $\mathrm{N}, \mathrm{S} 3 *$ & $\mathrm{~N}, \mathrm{~S} 3 *$ \\
\hline 4. & Pariangan & & & & & & S3* & $\mathrm{S} 3 *$ \\
\hline 5. & Rambatan & & & & $\mathrm{N}, \mathrm{S} 3 *$ & & $\mathrm{~N}, \mathrm{~S} 3 *$ & \\
\hline 6. & Limo kaum & & & & $\mathrm{S} 3 *$ & $\mathrm{~S} 2 *, \mathrm{~S} 3 *$ & & \\
\hline 7. & Tanjung emas & & & & $\mathrm{N}, \mathrm{S} 3 *$ & $\mathrm{~N}, \mathrm{~S} 3 *$ & & \\
\hline 8. & Padang gantiang & $\mathrm{N}, \mathrm{S}^{*}$ & & & & & & \\
\hline 9. & Lintau buo & & & & & & & \\
\hline 10. & Lintau buo utara & & & & $\mathrm{N}, \mathrm{S} 3 *$ & & & \\
\hline 11. & Sungayang & & & & & & & $\mathrm{N}, \mathrm{S} 3 *$ \\
\hline 12. & Sungai tarab & & & & & & & \\
\hline 13. & Salimpauang & & $\mathrm{N}, \mathrm{S} 3 * \star$ & & & & & \\
\hline 14. & Tanjung baru & & & $\mathrm{S} 3 *$ & & & & \\
\hline Luas & $\mathrm{S} 1$ & & & & & & & \\
\hline \multirow[t]{3}{*}{ (ha) } & S2 & & & & & 173 & & \\
\hline & S3 & 3.997 & 1.980 & 924 & 16.853 & 9.266 & 6.921 & 4.741 \\
\hline & $\mathrm{N}$ & 41 & 343 & 382 & 1.130 & 740 & 439 & 1.211 \\
\hline
\end{tabular}

Berdasarkan Tabel 3, dapat dilihat kesesuaian lahan untuk masing-masing komoditas unggulan, yaitu: karet memiliki kelas kesesuaian lahan S3 (3.997 ha) dan N (41 ha); kopi arabika S3 (1.980 ha) dan N (343 ha); kopi robusta S3 (924 ha) dan N (382 ha); kakao S3 (16.853 ha) dan N (1.130 ha); kelapa S2 (173 ha), S3 (9.266 ha), dan N (740 ha); cengkeh S3 (6.921 ha) dan N (439 ha); cassievera S3 (4.741 ha) dan N (1.211 ha); aren S3 (1.291 ha); tebu S3 (3.651 ha) dan N (4.019 ha); gardamunggu S3 (982 ha) dan N (444 ha); kapok S2 (34), S3 (1.038 ha) dan N (356 ha); merica S3 (4.912 ha) dan N (84 ha); pala S3 (4.603 ha) dan N (428 ha); vanili S3 (353 ha); dan kemiri S3 (1.366 ha) dan N (356 ha). Lahan dengan kelas kesesuaian lahan $\mathrm{N}$ tidak dapat dilakukan upaya perbaikan karena kelas kesesuaian lahan $\mathrm{N}$ merupakan kelas kesesuaian lahan permanen. Kelas kesesuaian lahan S3 dengan faktor 
penghambat ketersediaan air (wa), retensi hara (nr), ketersediaan hara (na), dan bahaya erosi (eh) dapat dilakukan upaya perbaikan. Namun jika faktor penghambat temperatur (tc) maka tidak dapat dilakukan upaya perbaikan. Iklim merupakan faktor pembatas yang sangat sulit untuk diperbaiki karena bersifat permanen (Widiatmaka et al. 2014).

Tabel 3. Kesesuaian Lahan Komoditas Unggulan Kabupaten Tanah Datar (Lanjutan)

\begin{tabular}{|c|c|c|c|c|c|c|c|c|c|}
\hline \multirow[t]{2}{*}{ No } & \multirow[t]{2}{*}{ Kecamatan } & \multicolumn{7}{|c|}{ Komoditas Unggulan } & \multirow[b]{2}{*}{ Kemiri } \\
\hline & & Aren & Tebu & $\begin{array}{l}\text { Garda } \\
\text { munggu }\end{array}$ & Kapok & Merica & Pala & Vanili & \\
\hline 1. & $\mathrm{X}$ koto & & & & & & & & \\
\hline 2. & Batipuh & & & & & & $\mathrm{N}, \mathrm{S} 3^{*}$ & & \\
\hline 3. & Batipuh selatan & & & $\mathrm{N}, \mathrm{S} 3 *$ & $\mathrm{~N}, \mathrm{~S} 2 * \mathrm{~S} 3 *$ & & N, S3* & & $\mathrm{N}, \mathrm{S} 3^{*}$ \\
\hline 4. & Pariangan & S3* & & & & & S3 & & \\
\hline 5. & Rambatan & & & & & $\mathrm{N}, \mathrm{S} 3 *$ & & & \\
\hline 6. & Limo kaum & & & & & & $\mathrm{S} 3 *$ & & S3* \\
\hline 7. & Tanjung emas & & & & & & & & \\
\hline 8. & Padang gantiang & & & & & & & & \\
\hline 9. & Lintau buo & & & & & & & & \\
\hline 10. & Lintau buo utara & & $\mathrm{N}, \mathrm{S} 3 *$ & & & & & & \\
\hline 11. & Sungayang & & & & & & & & \\
\hline 12. & Sungai tarab & S3* & & & & & & $\mathrm{S}^{*}$ & \\
\hline 13. & Salimpauang & & $\mathrm{N}, \mathrm{S} 3 * \star$ & & & & & & \\
\hline 14. & Tanjung baru & & $\mathrm{N}, \mathrm{S} 3 *$ & & & & & & \\
\hline Luas & S1 & & & & & & & & \\
\hline \multirow[t]{3}{*}{ (ha) } & S2 & & & & 34 & & & & \\
\hline & S3 & $\begin{array}{l}1.29 \\
1\end{array}$ & 3.651 & 982 & 1.038 & 4.912 & 4.603 & 353 & 1.366 \\
\hline & $\mathrm{N}$ & & 4.019 & 444 & 356 & 84 & 428 & & 356 \\
\hline
\end{tabular}

\section{Arahan rencana penggunaan lahan untuk komoditas unggulan perkebunan Kabupaten Tanah Datar}

Arahan perencanaan penggunaan lahan komoditas unggulan untuk seluruh kecamatan direncanakan pada lahan yang tersedia dan sesuai untuk pengembangan komoditas unggulan. Kecamatan yang memiliki satu komoditas unggulan, arahan pengembangan langsung kepada komoditas tersebut. Kecematan yang memiliki lebih dari satu komoditas unggulan, maka dipilih komoditas unggulan utama dan penunjang dengan mempertimbangkan: (1) pola tanam (aktual di lapang); (2) total produksi masing-masing komoditas unggulan; (3) total luas panen masing-masing komoditas unggulan; dan (4) kelas kesesuaian lahan komoditas unggulan sehingga didapatkan komoditas unggulan utama dan penunjang setiap kecamatan. Arahan perencanaan penggunaan lahan komoditas unggulan Kabupaten Tanah Datar disajikan Pada Tabel 4.

Tabel 4. Komoditas unggulan perkebunan utama dan penunjang Kabupaten Tanah Datar.

\begin{tabular}{|c|c|c|c|}
\hline \multirow{2}{*}{ No } & \multirow{2}{*}{ Kecamatan } & \multicolumn{2}{|c|}{ Komoditas Unggulan Perkebunan } \\
\hline & & Kompditas Unggulan Utama & Komoditas Unggulan Penunjang \\
\hline 1. & X koto & Kopi robusta & \\
\hline 2. & Batipuh & Pala & Kelapa \\
\hline 3. & Batipuh selatan & kakao & $\begin{array}{l}\text { Kelapa, cengkeh, cassievera, gardamunggu, } \\
\text { kapok, pala, dan kemiri. }\end{array}$ \\
\hline 4. & Pariangan & Cassievera & Cengkeh, aren, dan pala \\
\hline 5. & Rambatan & Kakao & Cengkeh dan merica \\
\hline 6. & Limo kaum & kakao & Kelapa, pala, dan kemiri \\
\hline 7. & Tanjung emas & kakao & Kelapa \\
\hline 8. & Padang gantiang & Karet & \\
\hline 9. & Lintau buo & & \\
\hline
\end{tabular}




\begin{tabular}{|c|c|c|c|}
\hline \multirow{2}{*}{ No } & \multirow{2}{*}{ Kecamatan } & \multicolumn{2}{|c|}{ Komoditas Unggulan Perkebunan } \\
\hline & & Kompditas Unggulan Utama & Komoditas Unggulan Penunjang \\
\hline 10. & Lintau buo utara & kakao & Tebu \\
\hline 11. & Sungayang & Cassievera & Aren \\
\hline 12. & Sungai tarab & Vanili & \\
\hline 13. & Salimpauang & Kopi arabika & Tebu \\
\hline 14. & Tanjung baru & Kopi robusta & Tebu \\
\hline
\end{tabular}

\section{KESIMPULAN}

Berdasarkan hasil dari penelitian ini dapat disumpulkan beberapa hal sebagai berikut: Komoditas unggulan tanaman perkebunan Kabupaten Tanah Datar berdasarkan analisis LQ dan SSA adalah: karet, kopi robusta, kakao, kelapa, cengkeh, cassievera, aren, tebu, gardamunggu, kapok, merica, pala, panili, dan kemiri.

Penggunaan lahan eksisting terluas di Kabupaten Tanah Datar secara berturut-turut adalah: hutan primer $(37,25 \%)$; hutan sekunder $(19,79 \%)$, dan sawah $(19,95 \%)$; kebun campuran (7,51\%). Sementara itu penggunaan lahan dengan luasan kurang dari $7 \%$ adalah tubuh air, lahan terbangun, ladang, lahan terbuka, dan semak belukar.

Lahan yang tersedia dan sesuai untuk pengembangan komoditas unggulan di Kabupaten Tanah Datar adalah sebagai berikut: karet (3.997 ha); kopi arabika (1.980 ha); kopi robusta (924 ha); kakao (16.853 ha); kelapa (9.439 ha); cengkeh (6.921 ha); cassievera (4.741 ha); aren (1.291 ha); tebu (3.651 ha); gardamunggu (982 ha); kapok (1.072 ha); merica (4.912 ha); pala (4.603 ha); vanili (353 ha); kemiri (1.366 ha).

Arahan rencana penggunaan lahan komoditas unggulan adalah: kopi robusta (Kecamatan X Koto dan Tanjung Baru); pala (Kecamatan Batipuh); kakao (Kecamatan Batipuh Selatan, Rambatan, Limo Kaum, Tanjung Emas, dan Lintau Buo Utara); cassievera (Kecamatan Pariangan dan Sungayang); vanili (Kecamatan Sungai Tarab); dan kopi arabika (Kecamatan Salimpauang).

Berdasarkan hasil penelitian ini maka disarankan beberapa hal, yaitu, dalam upaya pengembangan komoditas perkebunan di Kabupaten Tanah Datar disarankan agar pemerintah daerah fokus pada pengembangan komoditas unggulan utama di setiap kecamatan. Pada areal-areal yang berpotensi pengembangan agar dilakukan studi yang lebih rinci mengingat output SPL pada penelitian ini adalah 1:250.000.

\section{DAFTAR PUSTAKA}

[BPS] Badan Pusat Statistik. 2014. Kabupaten Tanah Datar Dalam Angka 2013. Batu Sangkar (ID): Kabupaten Tanah Datar.

[BBSDLP] Balai Besar Penelitian dan Pengembangan Sumberdaya Lahan Pertanian. 2011. Evaluasi Lahan Untuk Komoditas Pertanian. Bogor (ID): Jawa Barat.

[BPTP] Balai Pengkajian Teknologi Pertanian.2014. Kontribusi dan pertumbuhan PDRB sub sektor dan sektor pertanian selama lima tahun $(2007$ - 2011) di Sumatera Barat. http://sumbar.litbang.pertanian. go.id/ind/index.

Babalola TS, Oso T, Fasina AS, Gondanu K. 2011. Land evaluation studies of two wetland soils in Nigeria. International Research Journal of Agriculture Science and Soils Science 1 (6): 193 - 204.

Baja S. 2012. Perencanaan Tata Guna Lahan dalam Pengembangan Wilayah. Yogyakarta (ID): Andi

Blakely EJ. 1994. Planning Local Economic Development: Theory and Practice.2nd Edition. California (USA): International Education and Professional Publisher.

Boix LR, Zinck JA. 2008. Land use planning in the chaco plain (Burruyacu; Argentina). Part 1: Evaluating land use options to support crop diversification in an agricultural frontier area using physical land evaluation. Enviromental Management. 42: 1043 - 1063.

Ganasri BP, Dwarakish GS. 2015. Study of land use/land cover dynamics through classification algorithms for Harangi cathment area, Karnabaka strike. India. Aquatic Procedia. 4: 1413 - 1420.

Hansen MC, Defries RS, Twonshend JRG, Sohlberg R. 2000. Global land cover classification at $1 \mathrm{~km}$ spatial resolution using a classification tree approach. International Remote Sensing. 21: 1331 - 1364. 
Makaborang M, Geonadi S, Hadi P. 2009. Optimalisasi penggunaan lahan berdasarkan kelas kesesuaian lahan untuk pengembangan tanaman perkebunan (Studi Kasus: Kabupaten Sumba Timur). Jurnal Agritech. 29: $188-197$.

Ranya E, Abdul R, Fazel A, Noordin B, Siva K, Mohd A. 2013. Agriculture land suitability evaluator (ALSE): A decision and planning support tool for tropical crops. Computer and Computing Technologies in Agriculture. 93: 98 - 110.

Rustiadi E, Saefulhakim S, Panuju DR. 2011. Perencanaan dan Pengembangan Wilayah. Jakarta (ID): Crestpent Press dan Yayasan Pustaka Obor.

Rositadevy. 2007. Analisis Pengembangan Komoditas di Kawasan Agropolitan Batumarta Kabupaten Ogan Komering Ulu. [tesis] Bogor (ID): Institut Pertanian Bogor.

Widiatmaka, Sutandi A, Iswandi A, Daras U, Hikmat M, Krisnohadi A. 2014. Establishing land suitability criteria for cashew (Anacardium occidentale L.) in Indonesia. Applied and Enviromental Soil Science 2014: 1 14. 